\title{
Geometry, fractal dimension and settling velocity of flocs during flooding conditions in the Rhône ROFI
}

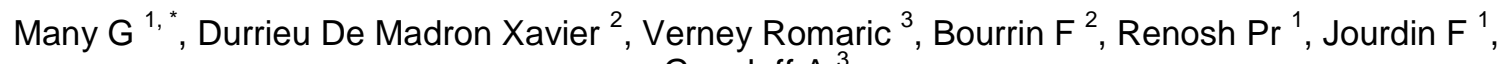 \\ Gangloff $A^{3}$
}

${ }^{1}$ SHOM, 13 Rue du Chatellier, CS92803, 29228, Brest, France

${ }^{2}$ CEFREM, UMR 5110 CNRS, UPVD, 52 Avenue Paul Alduy, 66860, Perpignan, France

${ }^{3}$ FREMER, DHYSED, ZI Pointe du Diable, 29280, Plouzané, France

* Corresponding author : G. Many, email address : gael.many@outlook.fr

\begin{abstract}
:
Regions Of Freshwater Influence (ROFI) are of particular interest in a source-to-sink approach in terms of sediment advection, settling, and deposition in the coastal zone. An experiment was carried out in the ROFI of the Rhône River in February 2016 to describe the properties of suspended particulate matter (SPM) during a flood event. A digital holographic camera (LISST-HOLO, 20-2000 $\mu \mathrm{m}$ ) was used to estimate the variability of fine sediment floc properties (size, nature and shape) formed in the Rhône mouth. An automatic image toolbox was developed to classify the different constituents of the SPM (as diatoms, bubbles and flocs) and to describe the diversity of floc shapes existing in the material in suspension. We estimated the fractal dimension (DF3D), the aspect ratio (AR) and the settling velocity of flocs (Ws). The estimated DF3D ranged between 2.0 and 2.5 highlights the complexity of floc shape, which was used as a proxy of the flocculation mechanism functioning in the Rhône mouth. Additionally, we performed a sensitivity analysis on the estimate of Ws using different shape-related coefficients $(\alpha / \beta)$ and primary particle size $(\mathrm{dP})$. The results highlighted the impact of the flocculation of fine sediments on the increase of Ws from 0.01 to $3 \mathrm{~mm} \mathrm{~s}-1$ when floc sizes increase from 30 to $500 \mu \mathrm{m}$. Ws showed a decrease of $41 \%$ considering the sphericity of flocs that emphasized the need to consider the floc shape to properly estimate their settling velocity. We showed that an increase of $\mathrm{dP}$ from 1 to $12 \mu \mathrm{m}$ induces a fivefold increase of Ws that showed the need for an adequate system to properly estimate the size of primary particles. These results emphasized the need to take into account such variability in future model of floc dynamics in ROFI to properly estimate plume sinking rate and SPM dynamics.
\end{abstract}

\section{Highlights}

Description of fine sediment floc properties in the Rhône River ROFI. Evidence of the diversity of floc shapes existing in the material in suspension. Flocculation increases of two orders the settling velocity of fine sediments. Evidence of the decrease of floc settling velocities considering floc shapes.

Keywords : Flocculation, Fractal dimension, Settling velocity, ROFI, Rhône 


\section{Introduction}

Regions of freshwater influence (ROFI) represent important transitional zones between the continent and the ocean, and are of particular interest in a source-to-sink approach in terms of sediment advection, settling, and deposition in the coastal zone. The understanding of the dynamics of suspended particulate matter (SPM) is critical to investigate biogeochemical processes, pollutant transport and regional sediment transport (Simpson and Sharples, 2012).

Observations of SPM generally show that coarse particles (as sand and medium to large silts) rapidly settle from the surface water toward the seabed where they contribute to form ephemeral sediment deposit in front of river mouths. Fine particles as clays and fine silts contribute to creating turbid structures as surface and bottom nepheloid layers, which spread over tens of kilometers on continental shelves. However, fine particles may also be aggregated owing to the sole or combined effect of SPM concentration, organic matter content, salinity gradient and turbulence (Fennessy et al., 1994; Wang et al., 2013). Thus the formed flocs may also contribute to the vertical particle flux from the surface to bottom water layers (Ayukai and Wolanski, 1997).

Settling of flocs can be altered because of changes in floc properties (size, shape, effective density). The monitoring of the variability of these properties requires non-intrusive, in-situ measurements of SPM to avoid alteration of floc properties (Mikkelsen and Pejrup, 2000; Chakraborti et al., 2003). For this purpose, several techniques have been proposed. For instance, settling velocities have been directly determined using in-situ imaging systems (INSSEV: Fennessy et al., 1994; Dyer and Manning, 1999; INSSECT: Mikkelsen et al., 2004; PICS: Smith and Friedrich, 2011; 2015). While these systems provide the settling velocity of flocs directly, they are difficult to implement because of their large size. Moreover, their deployments require calm weather conditions and are limited in time due to biofouling. Another method consists in deriving the settling velocity from theoretical models using floc Euclidian and fractal geometries determined by image analysis systems in laboratory (Thill et al., 1998; Billiones et al., 1999) and in-situ (Chen and Eisma, 1995).

The determination of the fractal dimension of flocs (i.e. a proxy of their 3D structure complexity) also permits the identification of mechanisms involved in the flocculation process. For instance, Thill et al. (1998) showed that flocs formed by diffusion-limited cluster aggregation (DLCA), such as Brownian aggregates and marine snow, have low fractal dimensions (i.e. complex and ramified shapes) whereas flocs formed by reaction limited cluster aggregation (RLCA), such as sludge flocs, have high fractal dimensions (i.e. compact shapes) (Bushell et al., 2002). The determination of such mechanisms is an important factor for evaluating collision rates, flocculation kinetics, and floc strengths and settling velocities (Chakraborti et al., 2007).

The in-situ monitoring of floc shapes has seldom been carried out (Winterwerp, 1998; Khelifa and Hill, 2006). Hence, models generally use the Stokes law and assume constant floc shape parameters (i.e. flocs are assumed to be spheres), causing substantial uncertainties in the calculation of floc settling velocities. These assumptions finally introduce errors in model predictions about floc dynamics and sediment budgets.

Here, we present new in-situ observations collected in the Rhône River ROFI in the northwestern Mediterranean Sea that enable the description of the size, nature, and shape of suspended particulate matter. The analysis of these observations aims to provide information on the Euclidian and fractal geometries of the SPM in order to: 1) classify the different constituents of the particles (as diatoms, flocs, and bubbles), 2) estimate the fractal dimension of individual flocs by image analysis, 
and 3) estimate the variability of their settling velocity using the shape-related coefficients. It is expected that these results will significantly advance our capability to model floc dynamics in the Rhône River ROFI and to generalize to other areas worldwide.

\section{Regional Settings}

The Gulf of Lions (NW Mediterranean) is a wide continental shelf mostly influenced by freshwater and particulate matter inputs from the Rhône River. The Rhône River is characterized by a mean annual discharge of $1700 \mathrm{~m}^{3} \mathrm{~s}^{-1}$ and typical annual flood with discharge $>5000 \mathrm{~m}^{3} \mathrm{~s}^{-1}$ (Maillet al., 2006). It supplies $80 \%$ of the sedimentary input to the gulf ( $7 \times 10^{6}$ tons per year) among which $70 \%$ is delivered during flood events (Pont, 1996; Bourrin and Durrieu de Madron, 2006; Sadaoui et al., 2016). Cauwet et al. (1990) and Garnier et al. (1991) detailed the Rhône River SPM composition and estimated the contribution of the clay fraction $(<4 \mu \mathrm{m})$ to $40 \%$, dominated by illite and chlorite. They also showed that the clay fraction increases during flood events (from $40 \%$ to more than $50 \%$ ) while organic content drastically decreases (from $15 \%$ to less than $5 \%$ ).

Miralles et al. (2005) showed that a fast vertical transfer of coarse particles (large silts and sands) takes place over the proximal prodelta (i.e. depth $<20 \mathrm{~m}$ ) where high sedimentation rates $(20-50 \mathrm{~cm}$ $\left.\mathrm{yr}^{-1}\right)$ are observed. Fine particles as clays $(<4 \mu \mathrm{m})$ and fine silts $(4-10 \mu \mathrm{m})$ are transported with surface plume and bottom nepheloid layers (BNL) whose structure and SPM concentration depend on environmental conditions (river discharge, oceanic currents, and wind conditions) (Many et al., 2017; Gangloff et al., 2017). In general, there is a seaward decrease in SPM concentration in the surface plume from $>20 \mathrm{mg} \mathrm{L}^{-1}$ next to the Rhône River mouth to $<5 \mathrm{mg} \mathrm{L}^{-1} 20 \mathrm{~km}$ offshore. A similar decrease was observed in the BNL with SPM concentration ranging from 10 to $1 \mathrm{mg} \mathrm{L}^{-1}$. To explain the settling of fine particles, previous studies have emphasized the role of aggregation phenomena by the electrochemical action of organic matter (Naudin et al., 1997) and salt along the dilution gradient of the surface river plume (Thill et al., 2001). More recently, Many et al. (2016; 2017) also highlighted the high proportion of 20-300 $\mu \mathrm{m}$ flocs in the suspended material close to the river mouth, for particle concentrations of $20 \mathrm{mg} \mathrm{L}^{-1}$. They showed that this proportion decreased seaward and inferred a likely (i.e. considering the bulk effective density of material in suspension) increase of the settling velocity by three orders of magnitude (from $\mu \mathrm{m} \mathrm{s}^{-1}$ to $\mathrm{mm} \mathrm{s}^{-1}$ ) thereby intensifying the sedimentation of fine sediments in the inner-part of the shelf.

\section{Material \& Methods}

A sea survey was carried out on board of the research vessel Tethys II, in front of the Rhône River mouth between February 11 and February 18, 2016 (Fig. 1a). The cruise took place during a major flood event (Fig. 1b). Thirty stations located along two sections parallel to the coast (i.e. along the 30 and $50 \mathrm{~m}$ isobaths respectively) and one section perpendicular to the coast were completed. They thereby cover the surface plume of the Rhône River (Fig. 1C). At all stations, particle properties, CTD and turbidity measurements were conducted over the whole water column ranging from 30 to $120 \mathrm{~m}$ (Fig. 1d). The in-situ size and geometry of the SPM was measured with a holographic camera associated with the instrumental package. Water samples were also collected at specific depths for the subsequent determination of the size of primary particles. 


\subsection{Background data}

Rhône River discharge - Rhône River discharge time-series (Fig. 1b) was measured at BeaucaireTarascon gauging station (Compagnie Nationale du Rhône - code V7200015), 50 km upstream of the river mouth. Data were provided by the Banque Hydro database.

Satellite data - Maps of surface SPM concentrations (Fig. 1c), with a $1 \mathrm{~km}$ resolution, were obtained from Moderate Resolution Imaging Spectroradiometer (MODIS) on Aqua satellite. Products, analysis and calibrations were provided by IFREMER Nausicaa services and OC5 IFREMER algorithms for SPM concentrations estimates from Gohin and Stanev (2011). Daily products were finally merged to obtain averaged information of surface SPM concentration during the period of interest.

Water column properties - Water pressure, temperature and conductivity were measured by profiling a Seabird 19+ CTD at each station. The density was derived using the EOS-80 algorithms (UNESCO, 1983). Turbidity was simultaneously measured with an Optical Back-Scatter (OBS) 3+ turbidimeter (at $850 \mathrm{~nm}$ ) and factory calibrated in Nephelometric Turbidity Units (NTU). Water samples were collected with vertical Niskin bottles mounted $1 \mathrm{~m}$ above the instrument package and triggered directly from the ship. Samples were collected at the surface $(1 \mathrm{~m}$ depth) and close to the seabed (2 mab, meters above bottom). SPM concentrations were determined by filtering seawater on GF/F filters ( $0.7 \mu \mathrm{m}$ nominal pore size) and gravimetric measurements following the method described in Aminot and Kérouel (2004). Turbidity measurements were then calibrated against SPM concentrations. We applied the relation from Gangloff (2017) who used a large dataset from 12 cruises (2011-2016): SPM $\left(\mathrm{mg} \mathrm{L}^{-1}\right)=2.0 *$ Turbidity $_{(\mathrm{NTU})}\left(\mathrm{RMSE}=3.9 \mathrm{mg} \mathrm{L}^{-1}\right.$ ). Filters were also used to determine particulate organic carbon (POC) content. Firstly, dry samples were decarbonated with repeated additions of $\mathrm{H}_{3} \mathrm{PO}_{4}(1 \mathrm{M})$ and $\mathrm{HCl}(2 \mathrm{M})$ until the end of effervescence. Then, $\mathrm{POC}$ contents were measured using a VarioMAX CN, Elementar Instrument. 
a)

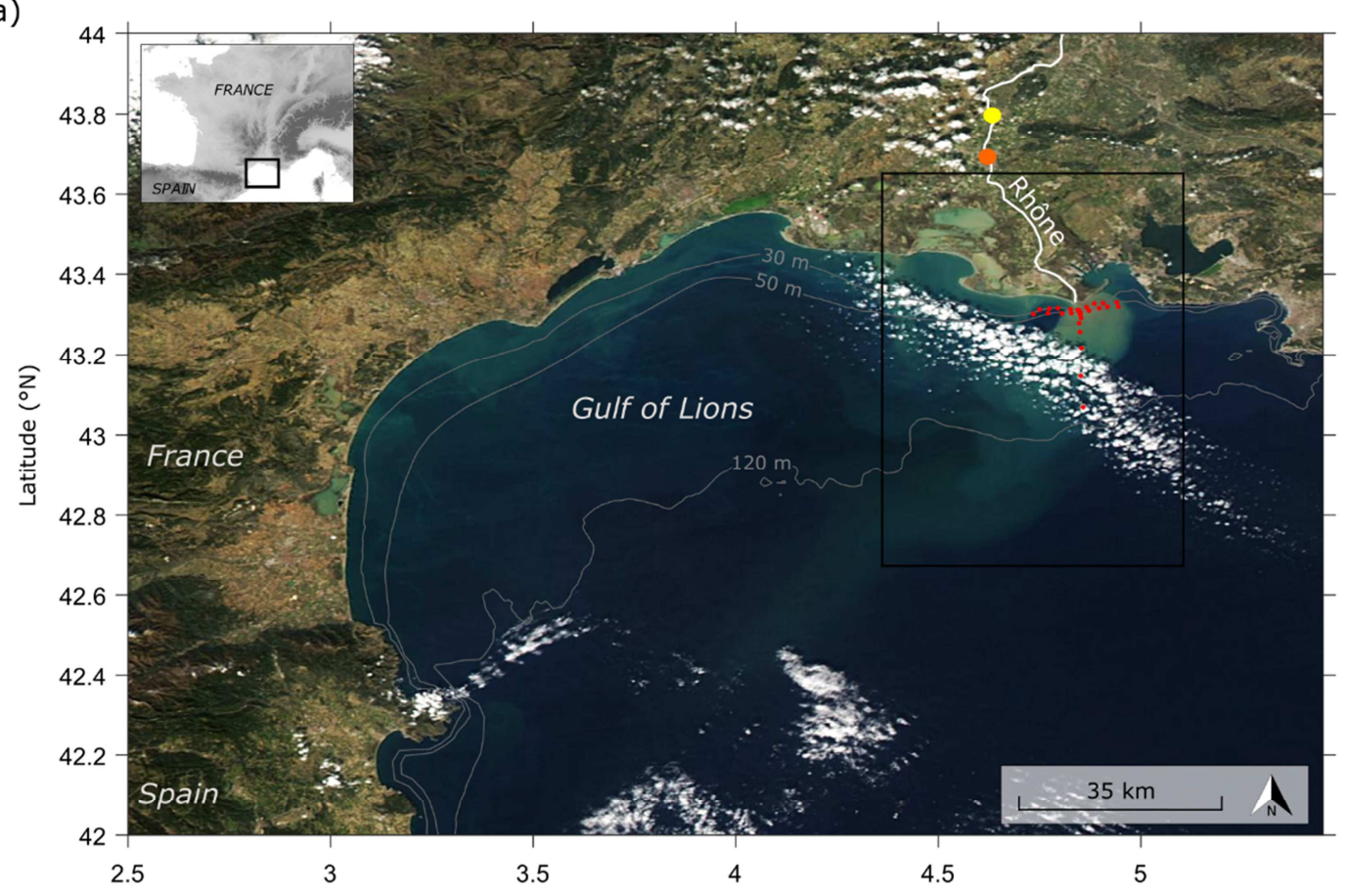

b)

Longitude $\left({ }^{\circ} \mathrm{E}\right)$

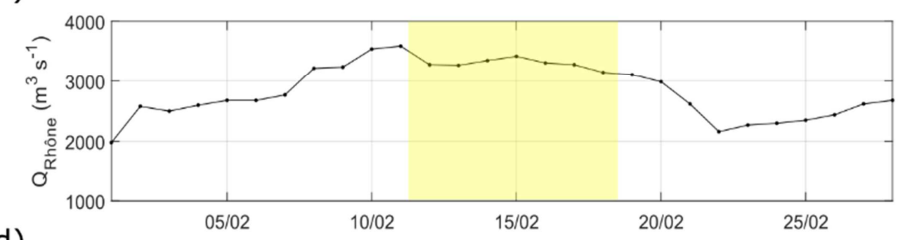

d)

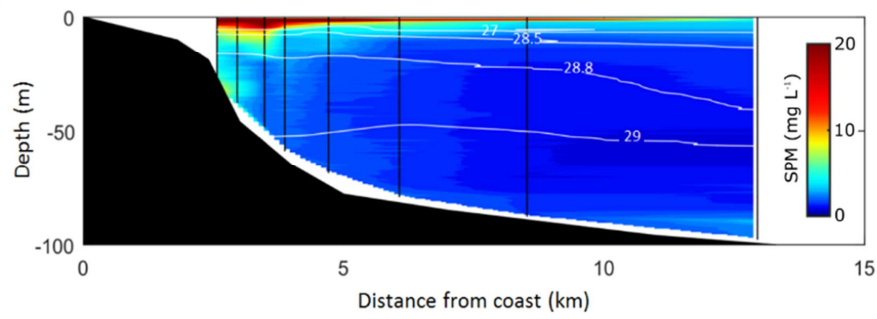

c)

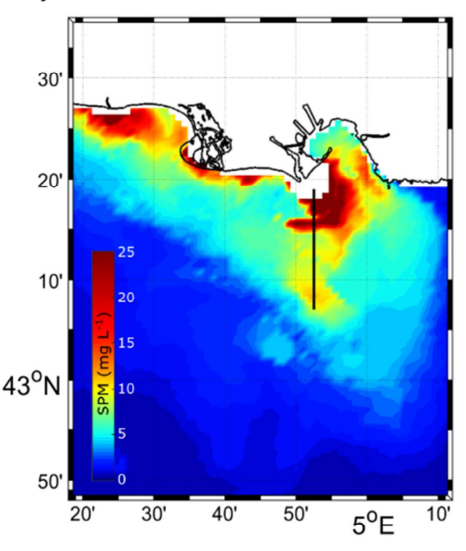

Figure 1: a) MODIS Aqua visible image from February 17, 2016. Red dots show the stations where CTD/Turbidity and LISST-HOLO measurements, as well as water sampling were made. The Rhône River is shown in white. Beaucaire and SORA stations are shown in yellow and orange, respectively. The 30, 50 and $120 \mathrm{~m}$ isobaths are shown in gray. b) Time series of the Rhône River water discharges. The period of the cruise is indicated in yellow. c) Surface averaged SPM concentrations derived from MODIS on February 11 to February 18, 2016. The black line shows the section presented in d). d) Cross-shelf section of SPM concentrations $\left(\mathrm{mg} \mathrm{L}^{-1}\right)$. Black lines show the position of the casts. Density contour lines are shown in white.

\subsection{SPM properties}




\subsubsection{Primary particle size distribution}

A Sequoia forward-scattering laser diffraction device (LISST-StreamSide, 1.9-387 $\mu \mathrm{m}$ range, $30 \mathrm{~Hz}$ ) was used at the SORA (Observatory Station Rhône in Arles) station, located in Arles, $40 \mathrm{~km}$ upstream of the river mouth, to estimate the particle size distribution (PSD) and volume concentration of Rhône River primary particles (Eyrolle-Boyer F., Pers. Comm.). PSD was estimated from a 1 month average of LISST measurements (November 2011) and is used here as a nominal distribution of the Rhône River material in suspension. Note that samples were not deflocculated before analyzing the PSD and some of clay particles could be already flocculated due to the presence of organic matter. A LISST-100X (type C, 2.50-500 $\mu \mathrm{m}$ range, $1 \mathrm{~Hz}$ ) was used on board to estimate PSD and volume concentration of primary particles composing the material in suspension in water samples. Water samples were deflocculated by ultrasonication for $5 \mathrm{~min}$. PSD was then estimated from $1 \mathrm{~min}$ average measurements using the "randomly shaped" Mie theory (Agrawal et al., 2008) and was converted to volume concentration (in $\mu \mathrm{L} \mathrm{L}^{-1}$ ). The relative fraction of each particle size class with respect to the total volume concentration (expressed in \%) was finally estimated.

\subsubsection{In-situ particle size distribution and geometry}

A Sequoia digital holographic camera (LISST-HOLO, 20-2000 $\mu \mathrm{m}$ range, $0.2 \mathrm{~Hz}, 4.4 \mu \mathrm{m}$ resolution) was used to study the volume, number and shape of large particles as complex aggregates and biological organisms (Graham and Nimmo-Smith, 2010; Graham et al., 2012; Davies et al., 2011; 2015). It uses a collimated red LASER reference beam $(659 \mathrm{~nm})$, which creates a hologram on a $7 * 5 \mathrm{~mm}$ CCD while scattered by the SPM. The holographic method permits the elimination of the typical depth of field issues encountered with other imagery systems like camera and microscope. It permits the analysis of SPM along a $50 \mathrm{~mm}$ path length without disturbance and therefore captures their real size and shape. Due to the low acquisition frequency of the holographic camera, two sampling depths were selected to collect statistically significant measurements. The first was at $5 \mathrm{~m}$ depth and the second at $\sim 1$ mab. Additionally, the measurements carried out during the descent/ascent of the instrument package were also used. Surface measurements ( $<5 \mathrm{~m}$ depth) were unusable due to the ambient light and the high turbidity. Thus, for each station, the average number of measurements is about 70 images.

Holograms were processed using Holo-Batch (Sequoia Inc.) software that uses routines developed by Graham and Nimmo-Smith (2010) and Owen and Zozulya (2000) and permits the reconstruction of SPM images from raw holograms. The different processing steps of the workflow are presented in Davies et al. (2015) (see Fig. 2). It consists in subtraction of the background image to reduce noise and remove stationary objects and numerical reconstruction of the background-corrected image following Owen and Zozulya (2000) to produce an ensemble of corrected images focused at different field depths through the sample volume. The final processed image of the SPM in the sample volume is finally constructed by combining each in-focus particle of each image through the sample volume.

Then, image segmentation is applied to determine the particles of interest. Several criteria are used to analyze only particles of interest. For instance, particles that contain continuous pixels on the border of the image are discarded. This criterion allows avoiding the analysis of only a portion of a particle that could result in errors in the estimate of the geometry (as size, perimeter and area) of the particle. In addition, a contrast threshold is used to discard low contrasted particles, which showed 
errors during binarization. A total of 2012 holographic measurements were made during the experiment. After particle selection, approximately 120000 particles were analyzed ( $82 \%$ of the total of particles) to characterize their properties.

a)

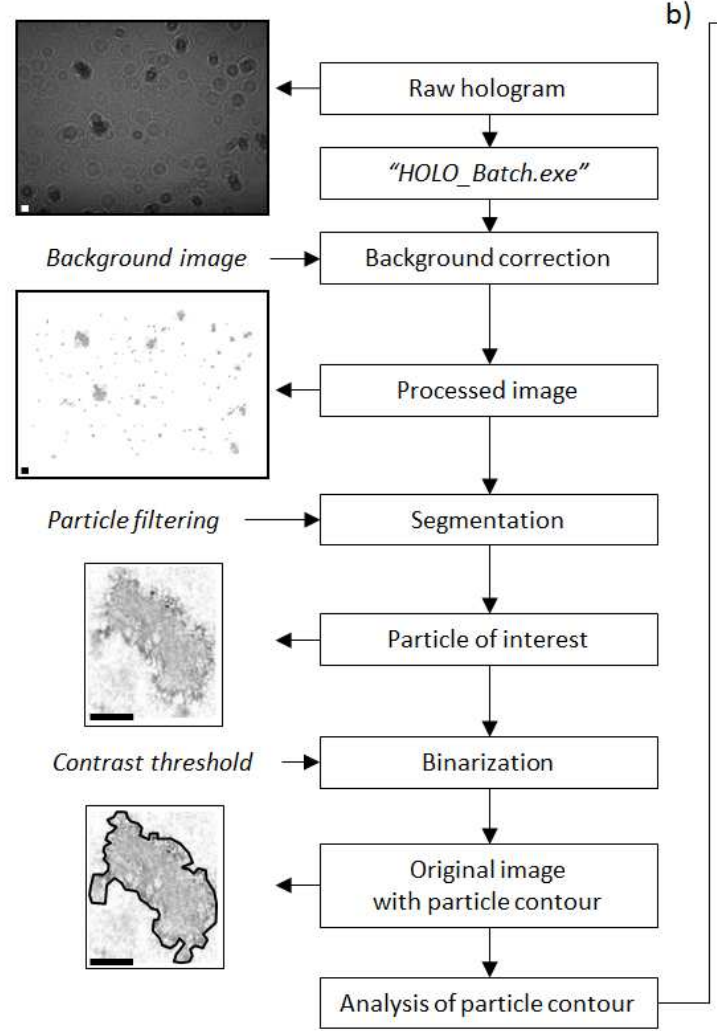

b)

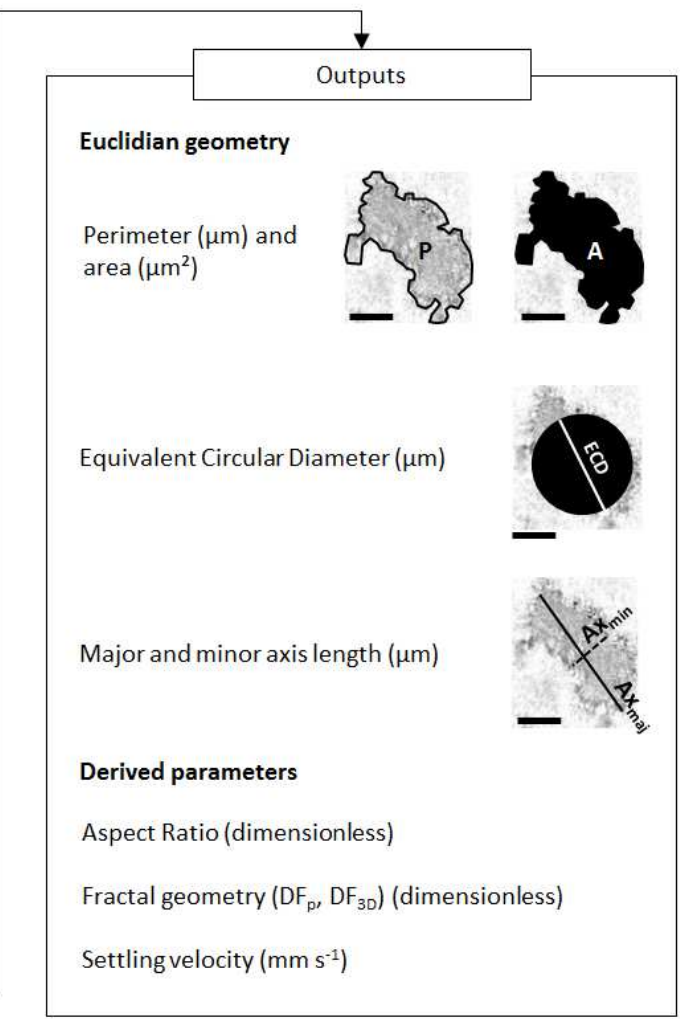

Figure 2: a) Conceptual view of the workflow of the processing of LISST-HOLO images and particle filtering, segmentation and binarization. b) Conceptual view of the determination of Euclidian geometry and derived parameters. Scale bar is $100 \mu \mathrm{m}$.

Based on LISST-HOLO binarized images, Euclidian and fractal geometry parameters were then determined by image analysis (Fig. 2).

Euclidian geometry - The projected area was determined using pixel counting of the binarized image of each particle. In addition, we determined the perimeter of the particle using pixel edges counting. The particle size was determined as the equivalent circular diameter (ECD) calculated from the projected area A following Eq. 1:

$E C D=2 \sqrt{A / \pi}$ Eq. 1

The aspect ratio (AR) was determined following Eq. 2 (Olson, 2011; ISO 9276-6). This parameter was used as a proxy of the particle sphericity.

$A R=\frac{A x_{\min }}{A x_{m a j}}$ 
where $A x_{\text {min }}$ and $A x_{\text {maj }}$ represent the minor and major axis of the particle respectively. According to this parameter, a spherical particle has an aspect ratio of one whereas an elongated particle has an aspect ratio that tends towards zero (Clavano et al., 2007).

Fractal geometry - We estimated the perimeter-based fractal dimension (called thereafter $\mathrm{DF}_{\mathrm{P}}$ ) based on the relation between the area and the perimeter $P$ of individual flocs assuming that $A=$ $\mathrm{P}^{2 / \mathrm{DFp}}$ (Eq. 3). This assumption has been used in previous studies (Maggi and Winterwerp, 2004; Vahedi and Gorczyca, 2011).

$D F_{P}=2 \frac{\log (P)}{\log (A)}$

Eq. 3

The value of $D F_{p}$ is equal to 1 for a perfect spherical Euclidean object, and $D F_{p}$ is 2 for a line (Spicer and Pratsinis, 1996; Tang, 1999). However, due to the resolution of the instrument (pixel size of 4.4 $\mu \mathrm{m}$ ), we determined a minimum $D_{\mathrm{p}}$ value of 1.45 for a perfect Euclidian object of approximately 20 $\mu \mathrm{m}$ size. This value decreased to 1.38 for a $50 \mu \mathrm{m}$ size object and to 1.32 for a $100 \mu \mathrm{m}$ size object.

Besides, the estimate of the 3D fractal dimension $\left(D_{3 \mathrm{D}}\right)$ from the perimeter-based fractal dimension $\left(D F_{p}\right)$ was derived following the relationship described in Lee and Kramer (2004):

$D F_{3 D}=-1.63 * D F_{P}+4.6$

Eq. 4

Following Eq. 4, the magnitude of $D F_{3 D}$ for a perfect spherical object $\left(D F_{p}=1\right)$ is found to be 2.97, which is close to the theoretical value of 3 . In coastal seas, fine-sediment flocs generally present a 3D fractal dimension between 1.8 and 2.6 (Dyer and Manning, 1999). Considering the instrument resolution (see above), maximum values of $2.25,2.35$ and 2.45 can be determined for 20,50 and 100 $\mu \mathrm{m}$ size objects, respectively.

Floc selection criteria - The aspect ratio parameter enables the discrimination of some populations of SPM (Davies et al., 2015). This parameter was used to automatically classify the different constituents (as bubbles, diatoms and flocs) of the SPM and permitted to select flocs only: low aspect ratios $(A R<0.1)$ were used as selection criterion to avoid the analysis of planktonic organisms as diatoms; high aspect ratios ( $A R>0.9$ ) were used as criteria to remove bubbles (see Fig. 3). Discarded particles based on these criteria were few (approximately 3000, i.e. $2.5 \%$ of the total number of analyzed particles) due to the over-abundance of flocs. Their removal is nevertheless needed to reduce the uncertainties on the estimates of the derived fractal dimension and related parameters. 


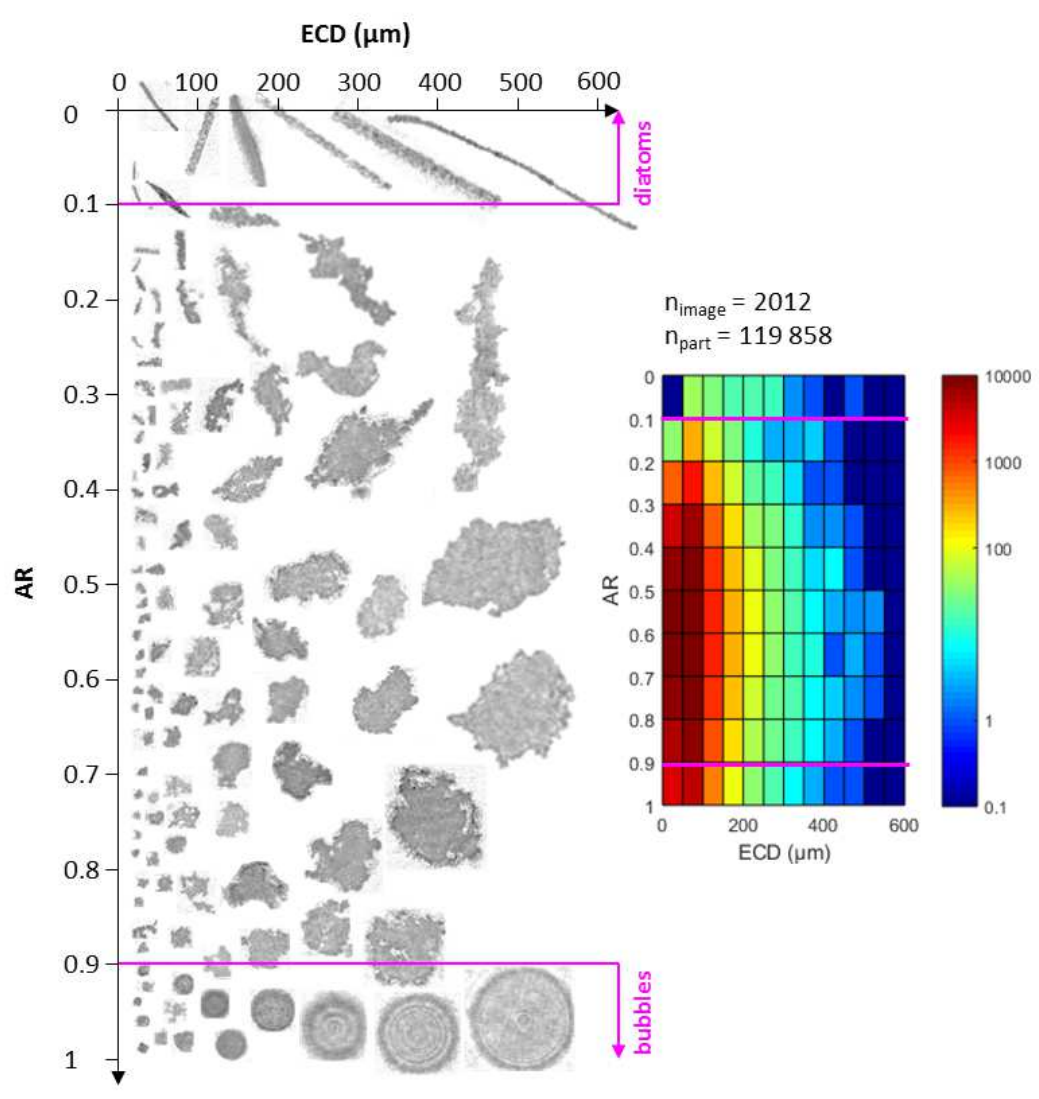

Figure 3: Variation of SPM aspect ratio (AR, dimensionless) as a function of the SPM equivalent circular diameter $(E C D, \mu \mathrm{m})$. Thresholds used to discard diatoms and bubbles are shown in magenta. The corresponding particle number distribution per size class is shown on the right panel. The number of images ( $\left.n_{\text {image }}\right)$ and particles ( $n_{\text {part }}$ ) analyzed is specified.

\subsubsection{Floc settling velocities}

We derived the settling velocity $\left(\mathrm{W}_{\mathrm{s}}\right.$ in $\left.\mathrm{mm} \mathrm{s}^{-1}\right)$ of each floc following the work of Winterwep (1998) (Eq. 5):

$W_{s}=\frac{\alpha}{18 \beta} \frac{\left(\rho_{p}-\rho_{w}\right) g}{\mu} d_{p}^{3-D F_{3 D}} \frac{E C D^{D F_{3 D^{-1}}}}{1+0.15 R^{0.687}}$

where $\alpha$ and $\beta$ are coefficients depending on the sphericity of the floc, $\rho_{p}$ is the density of a single particle (typically $2650 \mathrm{~kg} \mathrm{~m}^{-3}$ for mineral particles, see Boss et al., 2009), $\rho_{\mathrm{w}}$ the density of seawater (assumed to be constant and equal to $1028 \mathrm{~kg} \mathrm{~m}^{-3}$ due to the weak variability observed), $\mu$ the dynamic viscosity of seawater $\left(1.0810^{-3} \mathrm{~Pa} \mathrm{~s}\right), \mathrm{d}_{\mathrm{p}}$ the diameter of a primary particle, $\mathrm{DF}_{3 \mathrm{D}}$ the $3 \mathrm{D}$ fractal dimension of the floc, $g$ the gravitational acceleration $\left(9.81 \mathrm{~m} \mathrm{~s}^{-2}\right)$, ECD the floc equivalent circular diameter and $R$ the floc Reynolds number $\left(R=W_{s} E C D / v\right.$, where $v=1.0510^{-6}$ is the kinematic viscosity of seawater).

We made a sensitivity analysis on $\alpha / \beta$ and $d_{p}$ by varying one parameter at a time. To our knowledge, there is no accurate definition of $\alpha$ and $\beta$. We estimated $W_{s}$ using the assumption that $\alpha / \beta=1$ or $\alpha$ / $\beta=A R$. Besides, the value of $d_{p}$ is not clearly specified in the literature. We compare estimates of $W_{s}$ 
for $d_{P}=1,6$ and $12 \mu \mathrm{m}$ based on PSD from Rhône River and deflocculated measurements (see 4.2.1, Fig. 5).

\section{Results}

\subsection{SPM variability}

A flood of the Rhône River occurred during the days of measurements at sea (February 11-18, 2016). The mean discharge was $3500 \mathrm{~m}^{3} \mathrm{~s}^{-1}$ during the survey (Fig. 1a) that drastically increased the SPM concentration in front of the Rhône mouth within a turbid surface plume that spread southward (see Fig 1b). Surface SPM concentration observed from satellite had a maximum value of approximately $30 \mathrm{mg} \mathrm{L}^{-1}$ close to the river mouth and decreased seaward. The pycnocline, defined by the $27 \mathrm{~kg} \mathrm{~m}^{-3}$ isopycnal, delimits a vertical extension of the plume of about $10 \mathrm{~m}$ depth range. The turbidity in the plume progressively decreased seaward from 20 to $4 \mathrm{mg} \mathrm{L}^{-1}$ (Fig. 1c). Close to the seabed, a BNL of 20 $\mathrm{m}$ thick was present in the inner-part of the shelf (3-5 $\mathrm{km}$ off the river mouth) with turbidity decreasing seaward from 8 to $2 \mathrm{mg} \mathrm{L}^{-1}$.

\subsection{Suspended particle properties variability}

Many et al. (2016), who studied the spatial variability of the material in suspension in this area, showed that the PSD of primary particles was homogenous over the shelf, and did not notice any spatial trend in the floc shape using the AR parameter (i.e. AR ranged between 0 and 1 for all size classes wherever over the shelf). The data on ECD, $A R, D F_{3 D}$ and $W s$ of the present study highlight a similar lack of notable spatial trends (see Fig. 4), both horizontally (along- and cross-shore) and vertically (surface vs. bottom). The different parameters vary in restricted ranges and show high standard deviations when the data are combined by latitude. Hence, we considered all the water samples and the LISST-HOLO measurements collected during the cruise wherever their location, to characterize the SPM properties. This collection considerably increases the statistical significance of the results. 

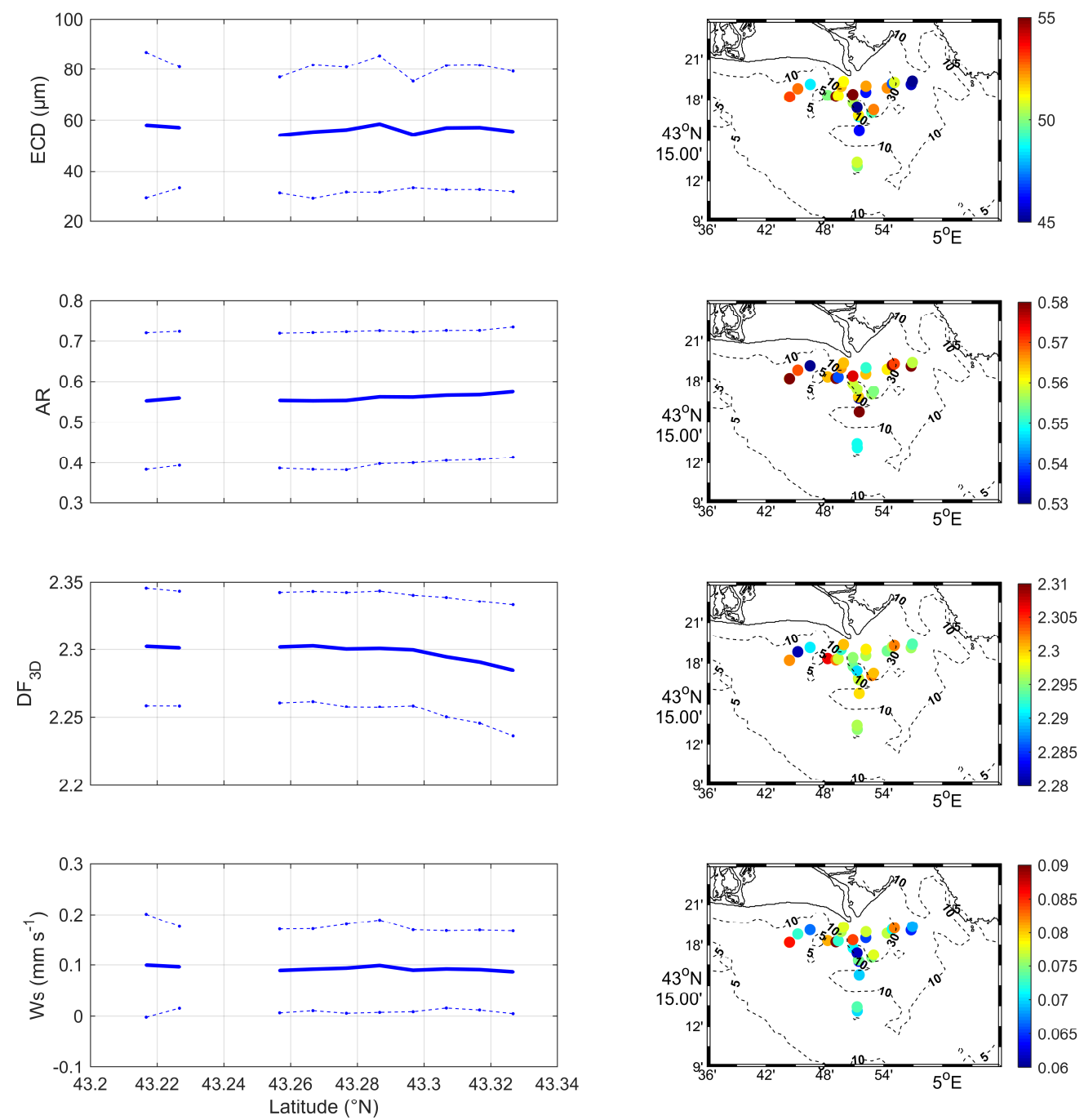

Figure 4: Left: Floc averaged properties as a function of the latitude. Standard deviations are shown by dashed lines. Right: Spatial distribution of floc averaged properties for surface measurements. SPM contour lines from satellite measurements are shown by black dashed lines. From top to bottom the floc properties: $\operatorname{ECD}(\mu \mathrm{m}), A R, D F_{3 D}, W s\left(\mathrm{~mm} \mathrm{~s}^{-1} ; d_{p}=1 \mu \mathrm{m} ; \alpha / \beta=A R\right)$.

\subsubsection{Particles size distribution}

Comparison of river and marine primary particles size distribution - The PSDs of primary particles measured in the Rhône River with the LISST-StreamSide and from water samples in the Rhône River plume with the on-board LISST-100X are shown on Fig. 5 . They are both characterized by a mode centered around $4-20 \mu \mathrm{m}$, which is typical of fine silts, and a probable contribution of the finest particles ( $<4 \mu \mathrm{m}$, at the lower limit of the instruments), which corresponds to clays. However, while organic contents were low (i.e. we estimated POC contents of about $3 \%$ ) it could have an impact by 
limiting the deflocculation by ultrasonication. The 4-20 $\mu \mathrm{m}$ could thus show flocculated clay particles by the organic matter as well as the presence of organic particles in suspension as phytoplankton.

In-situ particle size distribution from the LISST-HOLO images (see the red curve on Fig. 5) obtained in the entire water column differed significantly from the PSD of primary particles. It showed a broader and coarser mode ranging between 20 and $400 \mu \mathrm{m}$, which typically corresponds to flocs. The particle number distribution (PND) (Fig. 5 - bottom panel) followed a negative power law (except for the finest particles due to the resolution limit of the instrument) that underlined the low abundance of the largest flocs contrasting with their volumetric importance.
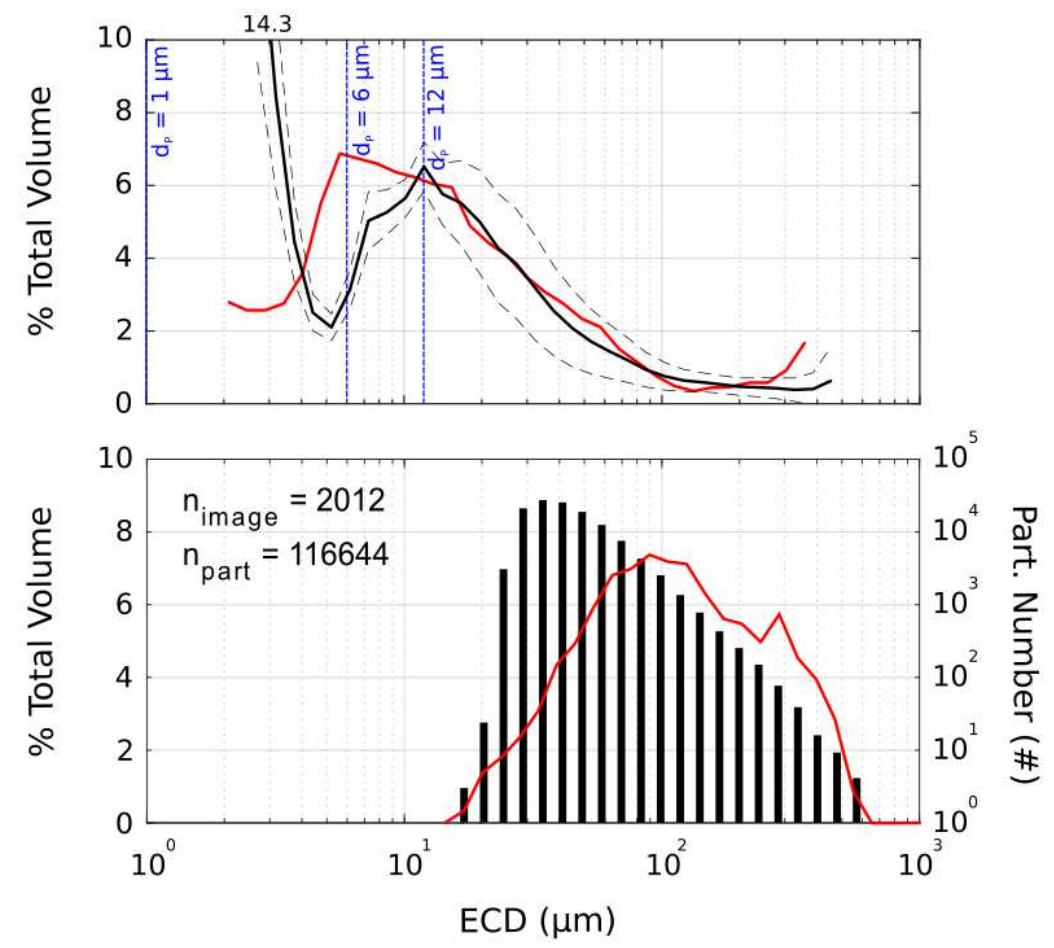

Figure 5: Top-panel: Volume PSD of SPM from the Rhône River using the LISST-StreamSide measurements (red) and deflocculated SPM from water samples using the LISST-100X measurements (black). The different values of $d_{p}$ used to estimate $W_{s}$ are shown in blue. Bottom panel: In situ floc volume PSD from LISST-HOLO measurements (red) and floc number distribution (black). The total number of images $\left(n_{\text {image }}\right)$ and flocs $\left(n_{\text {part }}\right)$ analyzed is specified.

\subsubsection{Floc fractal dimensions}

The qualitative and quantitative distributions of floc $\mathrm{DF}_{3 \mathrm{D}}$ are shown in Figure 6. The qualitative representation highlights the large diversity of floc shapes for the same size class, resulting in different fractal dimensions. Overall, $\mathrm{DF}_{3 \mathrm{D}}$ values range between 2 and 2.5. Large flocs with size over $100 \mu \mathrm{m}$ cover the whole range of fractal dimensions. The most abundant flocs with sizes between 20 and $150 \mu \mathrm{m}$ have less variable fractal dimensions and a mean value of 2.3. 


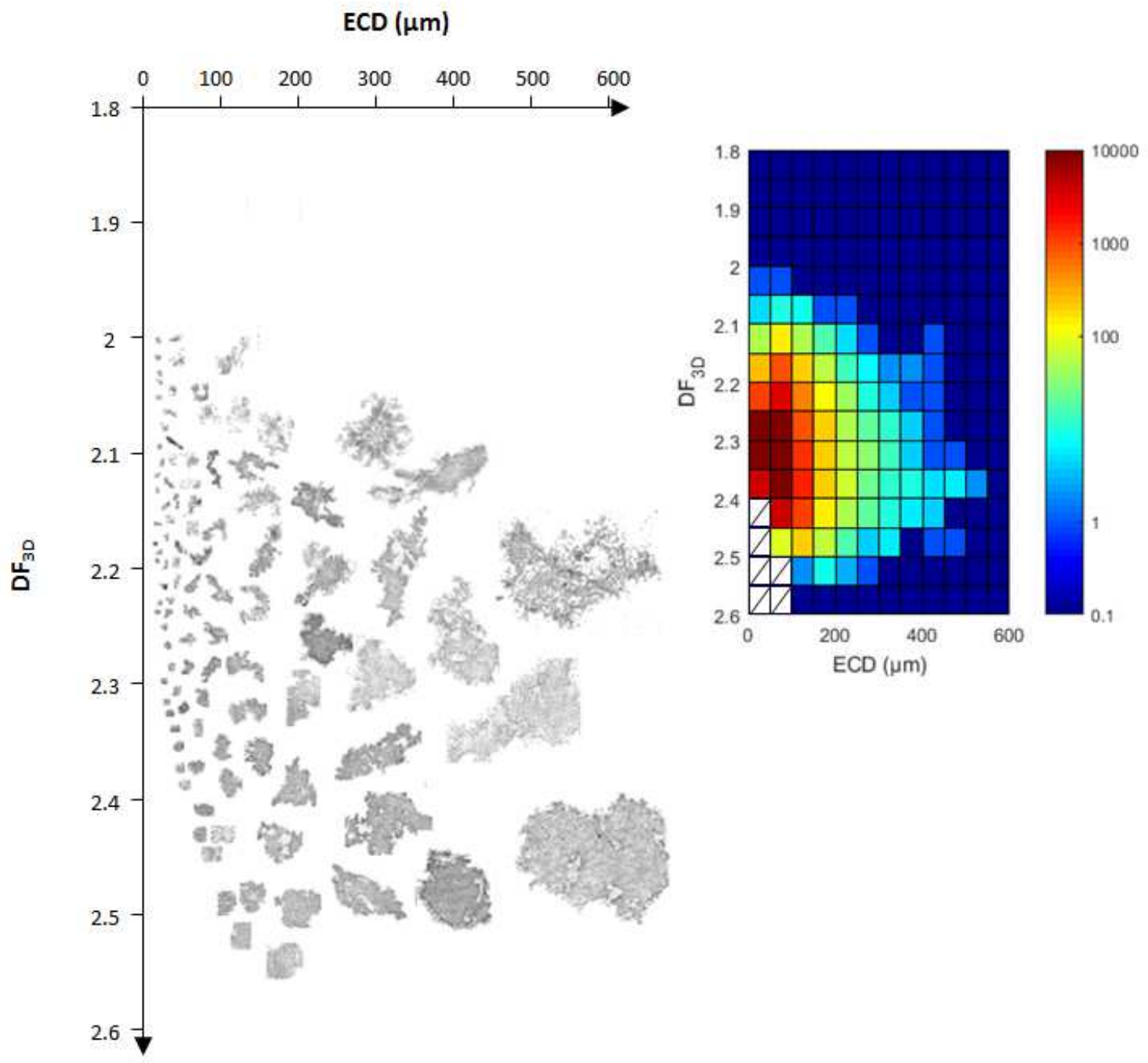

Figure 6: Visual distribution of the 3D fractal dimension of flocs $\left(D_{3 D}\right)$ as a function of the equivalent circular diameter of flocs $(E C D, \mu \mathrm{m})$. The corresponding particle number distribution per size class is shown on the right panel. The values of $\mathrm{DF}_{3 \mathrm{D}}$ not determinable due to the instrument resolution are shown in white.

\subsubsection{Floc settling velocities}

Estimated settling velocities for individual flocs derived from Eq. 5 and using different values of $d_{p}$ and $\alpha / \beta$ are shown in Figure 7 and 8 and the power law relationships $W_{s}=f(E C D)$ are summarized in Table 1.

Figure 7a shows the qualitative representation of the floc settling velocities as a function of their size. Assuming $\alpha / \beta=A R$ and $d_{p}=1 \mu \mathrm{m}$, the estimated settling velocities range between 0.01 and $3 \mathrm{~mm} \mathrm{~s}$ ${ }^{1}$ when floc sizes increase from 20 to $500 \mu \mathrm{m}$. It is noticeable that for the same size class different settling velocities can be observed depending on floc shapes, i.e. for $100 \mu \mathrm{m}$ floc size, $W_{s}$ ranges from 0.03 to $0.5 \mathrm{~mm} \mathrm{~s}^{-1}$. The decrease of the complexity of the floc shape (i.e. an increase of its fractal dimension) induces an increase in its settling velocity (Fig. 7b). In addition, a similar observation can 
be made depending on floc sphericity. Likewise, the increase of the sphericity of the floc (i.e. an increase of its aspect ratio) induces an increase of its settling velocity (Fig. 7c). These observations highlight the need to take into account such parameters in the estimate of their settling velocities, especially for large flocs.

a)

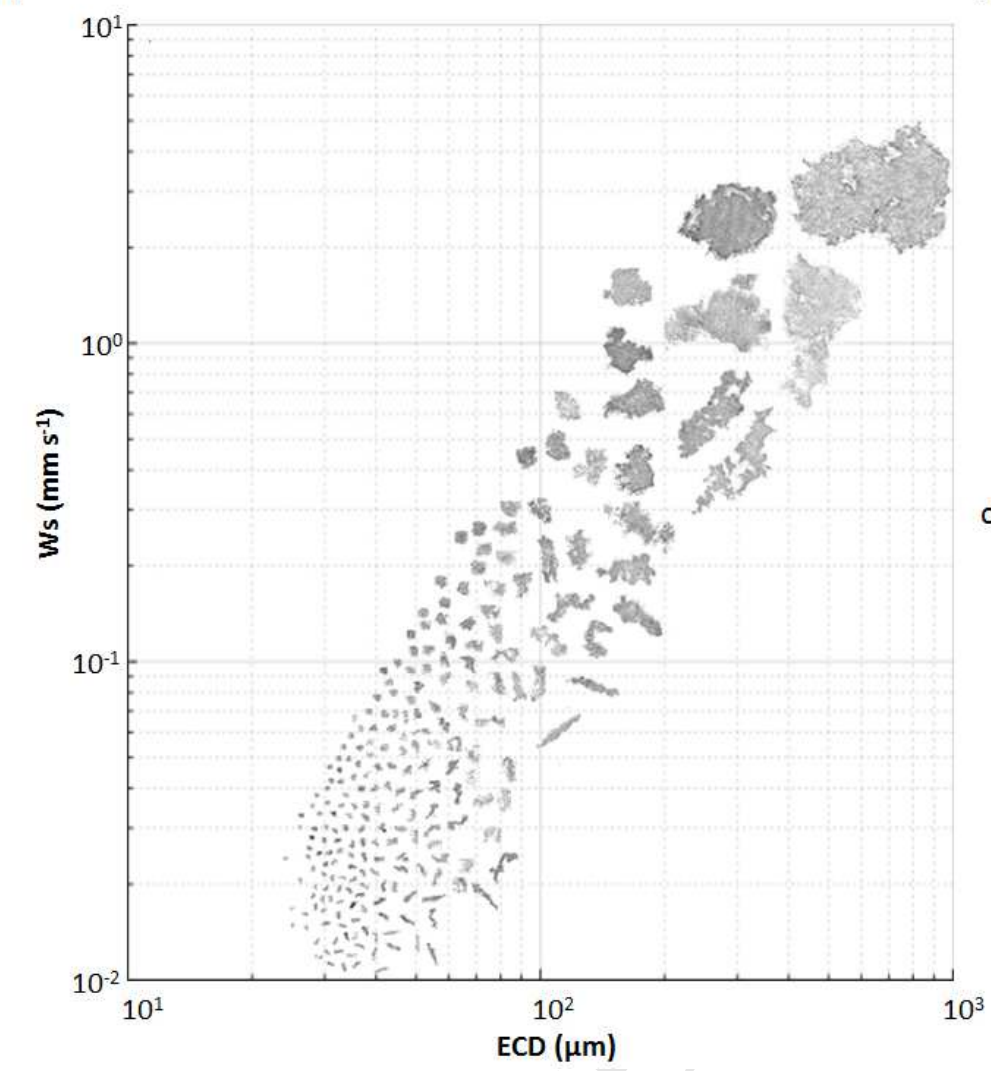

b)

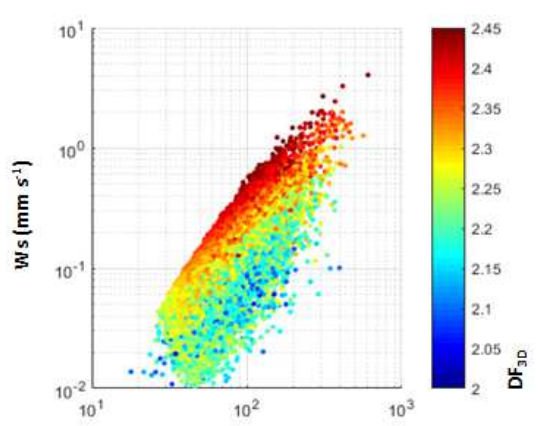

c)

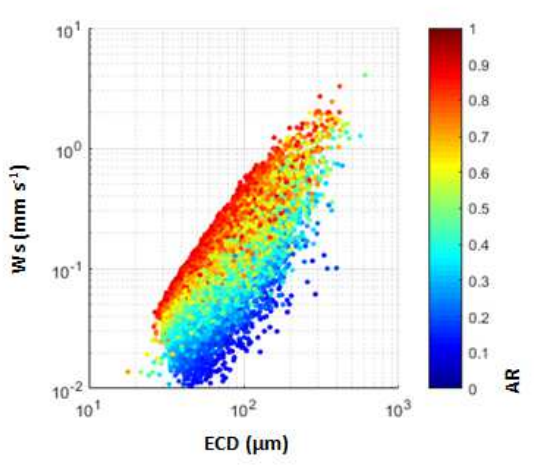

Figure 7: a) Visual distribution of floc settling velocities $\left(d_{p}=1 \mu \mathrm{m} ; \alpha / \beta=A R\right)$ as a function of the equivalent circular diameter of flocs $(E C D, \mu \mathrm{m})$. b) Quantitative distribution is shown on the right as a function of $b$ ) the fractal dimension and c) the aspect ratio.

Fig. 8 shows the results of the sensitivity analysis of Ws to the shape-related coefficient, $\alpha / \beta$, and to the diameter of the primary particle, $d_{p}$. Considering a constant value of $d_{p}(=1 \mu \mathrm{m})$, results show a decrease of the estimated floc settling velocities by $41 \%$ when $\alpha / \beta=$ AR with respect to $\alpha / \beta=1$. It also appears that decreasing the value of $\alpha$ / $\beta$ increases the variability of $W_{s}$ (see Fig. 8 left, Table 1 ). Considering an allocated value of $\alpha / \beta=A R$, the results show that the lower the primary particle size, the lower the floc settling velocities (Fig. 8 right). The average floc settling velocity increases twofold for $d_{p}$ varying from $1 \mu \mathrm{m}$ to $6 \mu \mathrm{m}$ and fivefold for $d_{p}$ varying from $1 \mu \mathrm{m}$ to $12 \mu \mathrm{m}$.

Power law relationships between the floc settling velocities (in $\mathrm{mm} \mathrm{s}^{-1}$ ) and the floc sizes $(\mu \mathrm{m})$ using different values of $d_{p}$ and $\alpha / \beta$ are summarized in Table 1. 

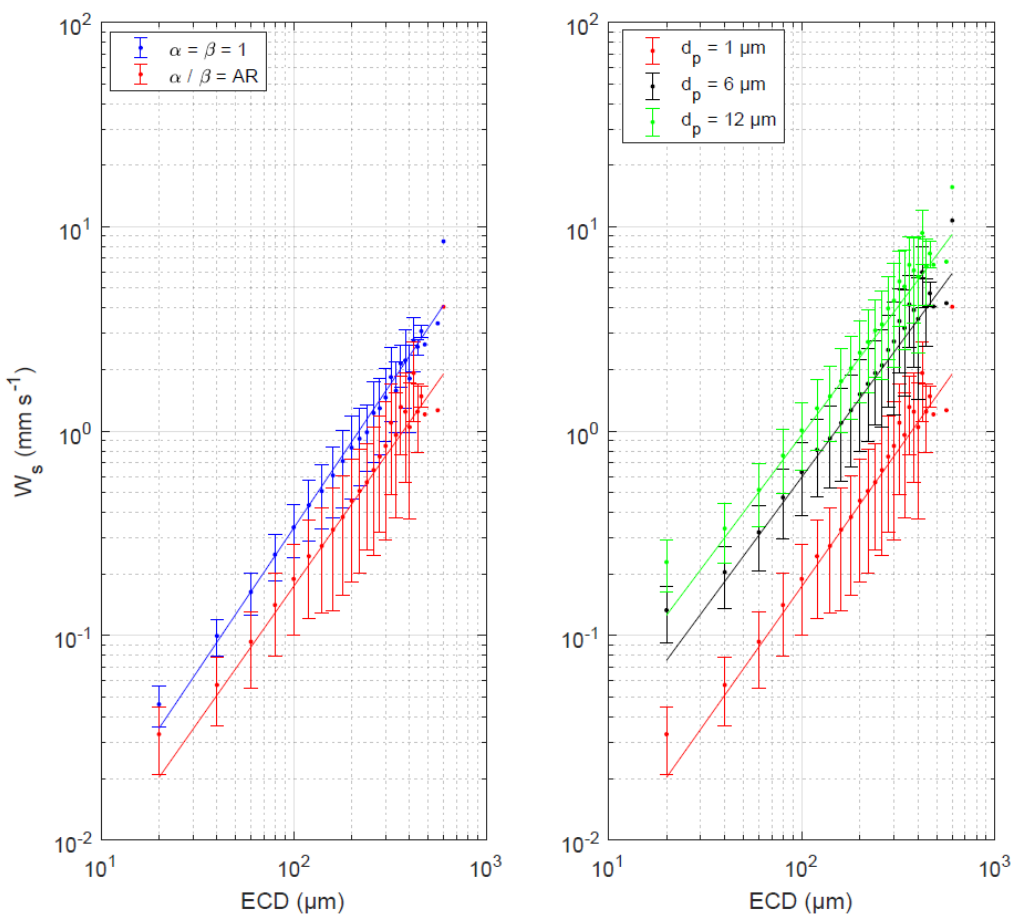

Figure 8: Binned data of floc settling velocities as a function of floc sizes for $\alpha=\beta=1$ and $\alpha / \beta=A R$ with $d_{p}=1 \mu \mathrm{m}$ (left) and for $d_{p}=1,6$ and $12 \mu \mathrm{m}$ with $\alpha / \beta=A R$ (right).

Table 1: Equations obtained from the least squares regression between binned data of estimated floc settling velocities as a function of floc sizes for different shape coefficients and primary particle sizes.

\begin{tabular}{ccccc}
\hline Shape Coefficients & $\mathbf{d}_{\mathbf{P}}(\boldsymbol{\mu m})$ & Ws expression $\left(\mathbf{m m ~ s}^{-1}\right)$ & $\mathbf{R}^{\mathbf{2}}$ & RMSE \\
\hline \multirow{3}{*}{$\alpha=\beta=1$} & 1 & $0.0006 \times \mathrm{ECD}^{1.38}$ & 0.977 & 0.076 \\
& 6 & $0.0026 \times \mathrm{ECD}^{1.33}$ & 0.984 & 0.062 \\
& 12 & $0.0048 \times \mathrm{ED}^{1.30}$ & 0.985 & 0.057 \\
\hline \multirow{3}{*}{$/ \beta=\mathrm{AR}$} & 1 & $0.0005 \times \mathrm{ECD}^{1.31}$ & 0.965 & 0.091 \\
& 6 & $0.0021 \times \mathrm{EDD}^{1.26}$ & 0.969 & 0.080 \\
& 12 & $0.0038 \times \mathrm{ECD}^{1.24}$ & 0.971 & 0.076 \\
\hline
\end{tabular}

The probability density function distributions of floc settling velocities for different floc sizes are presented in Figure $9\left(d_{p}=1 \mu \mathrm{m} ; \alpha / \beta=A R\right)$. We intend here to highlight the variability existing within a size class for different flocs. For this purpose we estimate a median settling velocity related to a standard deviation for the 20-125, 125-250 and $>250 \mu \mathrm{m}$ size classes, corresponding to the size classes generally used to describe microflocs, macroflocs and megaflocs (Van Leussen, 1994). 


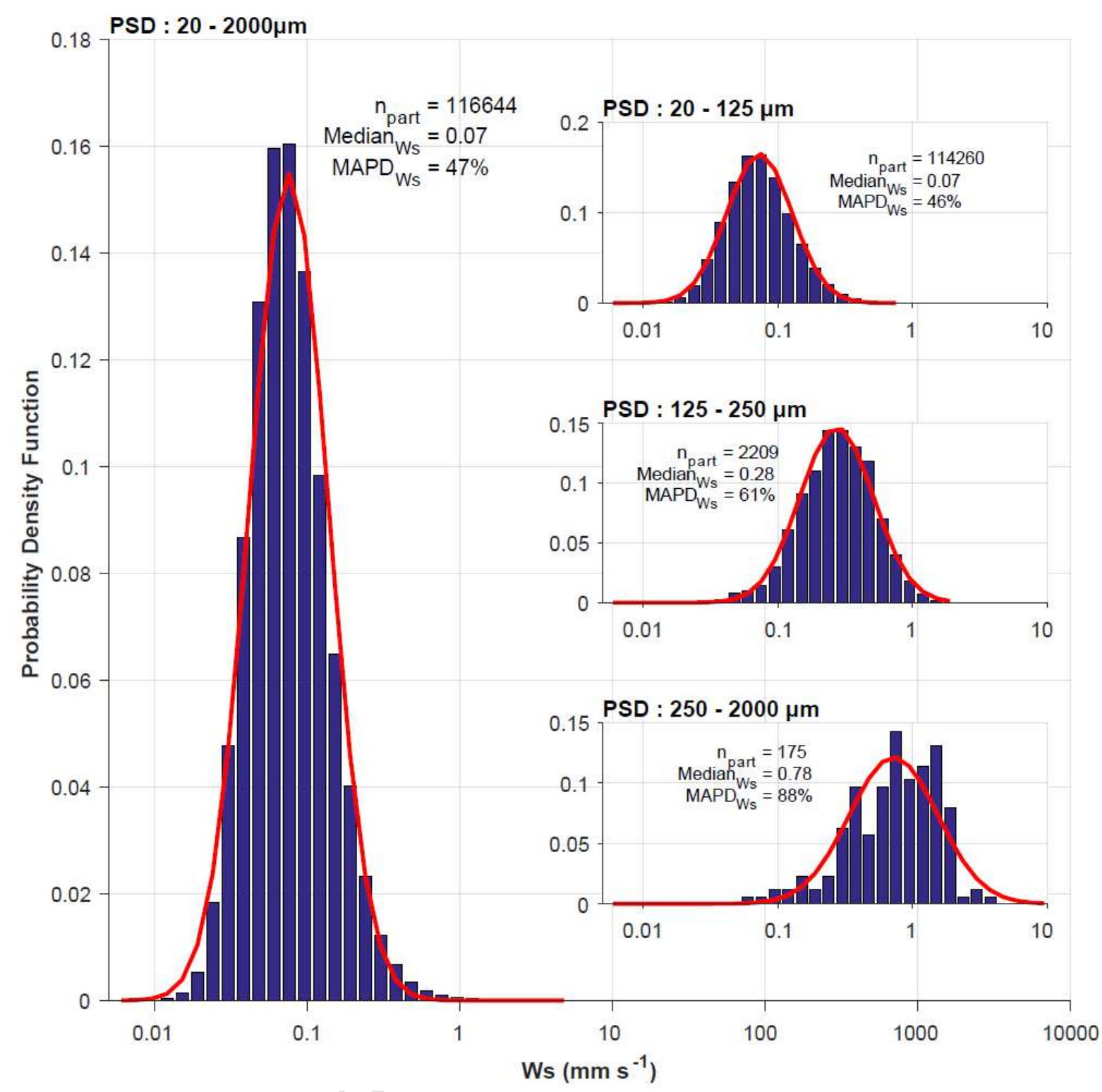

Figure 9: Probability density function (pdf) distributions of the estimated $W_{s}$ (in $\mathrm{mm} \mathrm{s}^{-1}$ ) using $d_{p}=1$ $\mu \mathrm{m}$ and $\alpha / \beta=$ AR. The pdf for all floc sizes is shown on the left. The pdf for three different size classes is shown on the right. The number of particles, the median value of $W_{s}$ and the mean absolute percentage deviation (MAPD $\mathrm{Ws}_{\mathrm{s}}$ in $\%$ using Median $_{\mathrm{W}_{\mathrm{s}}}$ as the forecast value) are specified on each plot. The Gaussian fit of the normalized logarithmic distribution of $\mathrm{W}_{\mathrm{s}}$ is shown in red. 


\section{Discussion}

Several studies have emphasized the necessity of non-intrusive, in-situ measurements to properly characterize the SPM without any disturbances, especially to characterize fragile fine-sediment flocs (Chakraborti et al., 2003; Mikkelsen et al., 2004). Based on LISST-HOLO in-situ measurements, we intend here to characterize the variability of SPM shape and structure in the Rhône River ROFI during a flood to classify the different constituents of the SPM, identify the mechanism of flocculation and describe the variability of the estimated floc settling velocity.

\subsection{In situ characterization of flocs}

LISST-HOLO measurements provide useful information on SPM properties that enable accurate analysis of SPM size, nature and shape. The holographic technique that permits the elimination of the typical depth of field issues encountered with other imaging systems (camera or microscope) enables the analysis of a lot of particles on each image through the sample volume. While it provides accurate information on the shape (aspect ratio, fractal dimension) of SPM, this system is however limited by its sampling frequency $(0.2 \mathrm{~Hz})$ and does not permit direct measurements of the SPM settling velocity. Nevertheless, it is expected that such observation will be soon possible by the development of the LISST-HOLO 2 (Sequoia Inc.), which will provide SPM measurements with a much higher sampling frequency $(10 \mathrm{~Hz})$.

The automatic particle classification (Figure 3 ) shows that the use of the aspect ratio seems to be a robust parameter to separate the different constituents of the SPM (diatoms, bubbles and flocs). It permits avoidance of a time-consuming manual classification and allows focusing only on the analysis of fine sediment flocs. Similar particle classification has been made in Davies et al. (2015), who used such a technique to separate sand, diatoms and bubbles. However, future work should focus on more elaborated, diversified material in suspension that could contain more complex shapes as phyto- and zooplankton as well as various sediment types (flocs and sand). This could be achieved on the basis of the work of Gorsky et al. (2010) using a digital zooplankton image analysis (ZooScan). It permits the classification of the zooplankton (ECD > $300 \mu \mathrm{m}$ ) using 40 shape attributes, among whom the perimeter fractal dimension and the minor and major axis extracted from the image analysis. Concerning the sediment types, the largest particles $(E C D>100 \mu \mathrm{m})$ such as sand could present higher fractal dimensions and aspect ratios than macroflocs (i.e. a higher sphericity and a lower structure complexity) (Zhou et al., 2017).

In our study, the material in suspension was mainly composed of flocs (see Fig. 5). Floc sizes observed were mainly centered around $20-500 \mu \mathrm{m}$, which is the typical floc size range in the Rhône ROFI (Many et al., 2016) and the Gulf of Lions (Curran et al., 2007; Bourrin et al., 2008; Durrieu de Madron et al., 2004, 2017). Our results are also consistent with observations carried out in others ROFIs as in the Ems, Rhine, Gironde, Tamar and Po estuaries where flocs of 30-600 $\mu \mathrm{m}$ were observed (Eisma, 1991; Fennessy et al., 1994; Fox et al., 2004). All these studies highlighted the importance of these flocs in the total volume concentration that significantly contributes to the vertical flux of fine particles. 


\subsection{Diversity of floc shapes}

Mechanisms responsible for the diversity of floc shapes are various and interact with each other. Processes like turbulence, differential settling, sediment concentration, organic content and biogenic aggregation may induce various floc shapes. McCave (1975) observed large flocs in the deep-sea probably induced by differential settling. Additionally, Winterwerp (1998) showed that the differential settling might not have a strong influence on the flocculation kinetics in estuaries. High turbulence shear may produce small spherical-shaped flocs, whereas low turbulence shear may be responsible for large elongated and ramified flocs (Verney et al., 2009). Manning and Dyer (2002) also highlighted the role of high sediment and organic concentrations in a turbulent environment that favored the formation of large spherical flocs.

This work follows the work of Lee and Kramer (2004) and is based on the estimate of the perimeterbased fractal dimension. The range of floc fractal dimensions (2.0 - 2.5; Figure 6) obtained is in line with previous studies such as Hill et al. (1998) in Glacier Bay, Alaska (DF 2.4), Dyer and Manning (1999) in the Elbe Estuary and Maggi et al. (2006) in the Tamar Estuary (DF 2.0 - 2.5). It is noticeable that our values are comparable with the ones obtained by Thill et al. (1998) with turbulence shearinduced aggregates (also called orthokinetic aggregation) formed in the laboratory.

Our estimates contrast with the 3D fractal dimension of aggregates formed in a diffusion limited cluster aggregation (DLCA) (as marine snow, $\mathrm{DF}_{3 \mathrm{D}}<2.0$; Thill et al. 1998) and of aggregates formed in reaction limited cluster aggregation (RLCA) (as sludge flocs formed in lime softening process, $\mathrm{DF}_{3 \mathrm{D}}>$ 2.5; Vahedi and Gorczyca, 2011). This contrast highlights the complexity of the intermediate floc shapes formed in the Rhône estuary, i.e. between the ramified shape of the marine snow and the compact, spherical shapes of sludge flocs. It also provides specific information on the flocculation mechanism operating in the Rhône estuary. While in a DLCA approach flocs are rapidly formed ( $\sim$ seconds/minutes) in which all collisions between particles are successful, the flocculation kinetics operating in the Rhône estuary could be slower ( hours) and a greater number of collisions are probably necessary to form large aggregates (Chakraborti et al., 2007; Mikes and Manning, 2010). These results could highlight the role of the SPM concentration in the change of floc sizes. A high SPM concentration could favor the flocculation mechanisms operating in the Rhône ROFI, enhancing the collision between fine cohesive particles.

However, the role of the salinity gradient in the change of Van der Waals forces between fine cohesive sediments might also play a role in the flocculation mechanism. We did not find any significant link between the variability of floc shapes and the salinity gradient. Based on the work of Mikes and Manning (2010) in the Seine and Gironde estuaries, future work should focus on the role of each parameter (i.e. SPM concentration, salinity gradient, level of turbulence and organic matter contents) in the dynamics of flocculation (i.e. number and size of flocs) and the shape (aspect ratio and fractal dimension) of flocs formed in the Rhône ROFI.

Our results have shown the diversity of floc shapes existing within the material in suspension in the Rhône ROFI during a flood. This shape diversity implies the importance of using a randomly shaped algorithm process to invert the particle size distribution from in situ light scattering using the Mie theory described in Agrawal et al. (2008). The results also highlight the importance of the individual flocs characterization to monitor their shape parameters and estimate their settling velocities following the equation of Winterwep (1998). 


\subsection{Impact of the diversity of floc shapes in floc settling velocities}

The material in suspension in the Rhône ROFI shows a large diversity in floc shapes that, in turn, affects their settling velocity. Based on the Winterwep (1998) equation we have shown that considering the floc fractal dimension (i.e. its shape complexity) and aspect ratio (i.e. its sphericity), different settling velocities can be observed for the same floc size (Fig. 7). Both shape-related coefficients have different impacts on the variability of floc settling velocities. While the aspect ratio parameter is a discriminatory factor for all particles (i.e. the more elongated, the less the estimated settling velocity), the fractal dimension is discriminatory only for the largest particles (ECD > $100 \mu \mathrm{m}$ ). Complex spherical particles could settle more rapidly than simple elongated particles. This could translate a degree of relative importance for each shape parameter.

In addition, the sensitivity analysis of the settling velocity to the shape of flocs $(\alpha / \beta)$ and diameter of a single particle $\left(d_{p}\right)$ shows significant changes. Our results highlighted an average decrease of $41 \%$ of the settling velocity when considering the sphericity of the floc (i.e., $\alpha / \beta=A R$, instead of the commonly used value $\alpha / \beta=1$ for spherical particles). The choice of the AR parameter as a main floc shape coefficient thus appears relevant. It ranges from 0 to 1 from a line to a perfect sphere as suggested by Winterwep (1998). Contrary to other parameters such as the circularity and the solidity, the floc shape coefficient is less dependent on the instrument resolution and the particle size. The implication is that future studies should monitor floc shapes ( $D F_{3 D}$ and $A R$ ) by image analysis and take into account such parameters in their estimate.

The primary particle size $\left(d_{p}\right)$ will obviously vary considerably between different estuaries and possible also both spatially and temporally within an estuary. Van Leussen (1994) suggested a value of $4 \mu \mathrm{m}$ for Ems mud, Curran et al. (2007) estimated to $5 \mu \mathrm{m}$ the size of a single particle in the Gulf of Lions, whereas Khelifa and Hill (2006) assumed a polydisperse single particle size distribution where $d_{p}=d_{50}$, the median size of component particles within flocs. The same authors also compared their results with theoretical values of $d_{p}=0.05,1$ and $20 \mu \mathrm{m}$ respectively and finally recommend a value of $d_{p}=1 \mu \mathrm{m}$. In this work, we estimated $W_{s}$ for $d_{p}=1,6$ and $12 \mu \mathrm{m}$ to compare and discuss the sensitivity to this parameter. The estimated settling velocity significantly increases with increasing size of single particles. This result highlights the need to perform accurate measurements of the primary PSD using adequate particle size analyzer. Systems used are generally limited in small size classes $(<2 \mu \mathrm{m})$ that do not permit the accurate measurements of the clay fraction. Future works should focus on this by establishing the primary PSD from $\mathrm{nm}$ to $\mathrm{mm}$, as well as mineralogical analysis.

Assuming $\alpha / \beta=A R$ and $d_{p}=1 \mu \mathrm{m}$, our results emphasize the role of flocculation in the increase of floc settling velocities (Fig. 9). The estimated settling velocity of flocs increased by one order of magnitude between flocs smaller than $125 \mu \mathrm{m}$ (median Ws $=0.07 \mathrm{~mm} \mathrm{~s}^{-1}$ ) and flocs larger than 250 $\mu \mathrm{m}$ (median $\mathrm{Ws}=0.78 \mathrm{~mm} \mathrm{~s}^{-1}$ ). Due to their rapid sinking rate, large flocs can reach the bottom nepheloid layer generally observed in front of the Rhône mouth (Many et al, 2016) in less than a day. The role of flocculation in the increase of fine sediments settling velocity has also been observed in situ in the Gulf of Lions by Curran et al. (2007) and in others ROFls such as in the Pearl (Xia et al., 2004) and the Po (Fox et al., 2004) estuaries. The general relations between the settling velocities versus the floc sizes obtained in this study are in line with those obtained in others areas and for different conditions (see Fig. 10 - Table 2). While the slopes obtained in this work differ significantly from the one presented in Xia et al. (2004) in the Pearl Estuary, they are particularly coherent with the work of Fox et al. (2004) in the Po Estuary (Mediterranean), which corresponds to a system similar to ours (i.e. a micro-tidal area and a similar river discharge). This observation could highlight a 
general trend existing between the Mediterranean Rivers, which can differ from other systems such as in high latitude or macro-tidal areas.

Our estimates also differ significantly from the work of Curran et al. (2007) who quantified the floc settling velocities over the Gulf of Lions' shelf. This later work was carried out during the spring and stratified periods with low rivers discharges that could explain the differences observed. Floc properties were possibly different during that work due to higher organic contents (as marine snow), no salinity gradient and a lower SPM concentration. This could nevertheless imply a change of floc properties along the shelf (i.e. floc shapes and effective densities) and future work could focus on the monitoring on the variability of floc properties from the Rhône River ROFI and transported toward the shelf.

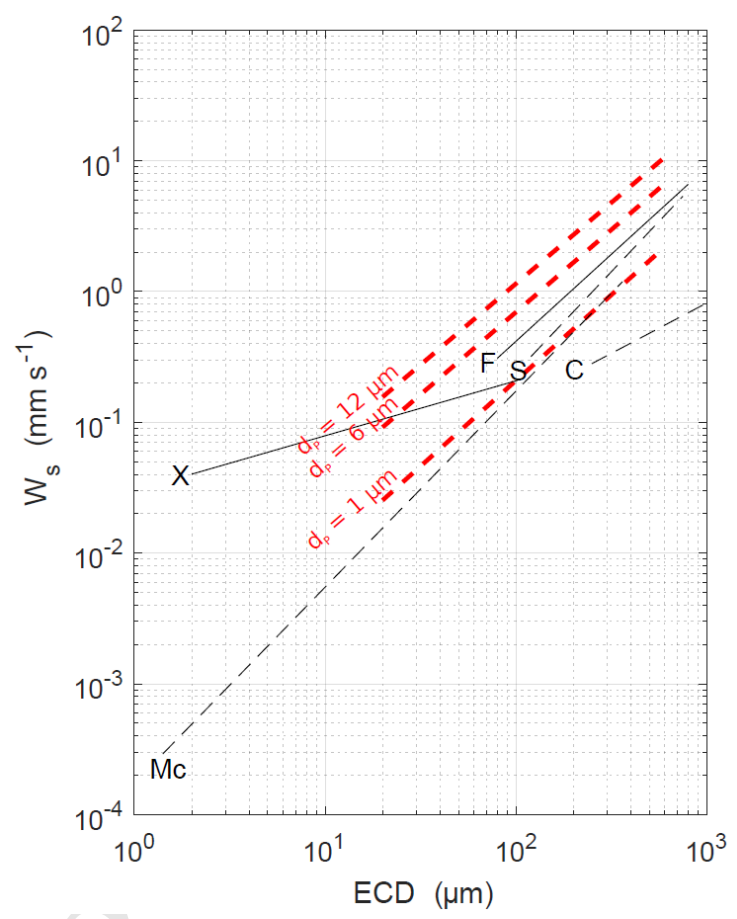

Figure 10: The established size versus settling velocity relationship (red dashed lines for $d_{p}=1,6$ and $12 \mu \mathrm{m}$ and $\alpha / \beta=\mathrm{AR}$ ) are compared with those of others studies in others areas and different conditions. Studies are marked as follows: $M c=$ McCave (1975) from the deep sea, $S=$ Sternberg et al. (1999) from the California continental shelf, $F=$ Fox et al. (2004) from the Po ROFI, $X=$ Xia et al. (2004) from the Pearl Estuary, $C=$ Curran et al. (2007) from the shelf of the Gulf of Lions.

Table 2: Comparison of the slopes obtained between data of floc settling velocities as a function of floc sizes for different studies $(\alpha / \beta=A R)$.

\begin{tabular}{cccc}
\hline Study & Area & $\mathbf{W}_{\text {s }}$ slope & $\mathbf{R}^{\mathbf{2}}$ \\
\hline This study & Rhône ROFI & $\mathbf{1 . 2 4 - 1 . 3 1}$ & $\mathbf{0 . 9 6 - 0 . 9 7}$ \\
McCave, 1975 & Deep Sea & 1.50 & N/A \\
Sternberg et al., 1999 & California shelf & 1.54 & 0.61 \\
Fox et al., 2004 & Po ROFI & 1.33 & 0.97 \\
Xia et al., 2004 & Pearl ROFI & 0.42 & 0.25 \\
Curran et al., 2007 & GoL shelf & 0.77 & 0.97 \\
\hline
\end{tabular}




\section{Conclusion}

This experiment provided a unique view of the suspended particle properties in the Rhône ROFI during a flood event. The use of a holographic camera in line with an automatic image processing system enabled the classification of the different constituents of the SPM (flocs, bubbles, diatoms) and to detail the shape of fine sediment flocs. Our results emphasized the abundance of flocs (20-500 $\mu \mathrm{m})$ in the material in suspension and their general non-spherical shape.

The range of the floc fractal dimensions observed $\left(\mathrm{DF}_{3 \mathrm{D}} \sim 2.0-2.5\right)$ provided information on the flocculation mechanism. It appeared that flocs formed in the Rhône estuary have an intermediate shape complexity between the marine snow form in DLCA and of sludge flocs formed in RLCA. This result could possibly highlight the slow kinetic flocculation ( hours) as well as the role of different parameters on the flocculation (as SPM and organic concentration, salinity gradient and turbulence) operating in the estuary.

The diversity of floc shapes highlighted the need for a randomly-shaped algorithm in order to model floc particle size distribution. A sensitivity analysis of the equation for floc settling velocity has been made considering the floc shape ( $\alpha / \beta=1$ vs. $\alpha / \beta=A R$ ) and various values of primary particles size $\left(d_{p}=1,6\right.$ and $\left.12 \mu \mathrm{m}\right)$. We estimated a $41 \%$ decrease of the floc settling velocity while considering the AR parameter as a main shape coefficient that emphasizes the need to take into account such a parameter in the equation of floc settling velocities. The increase of $d_{p}$ from 1 to $12 \mu \mathrm{m}$ induced a fivefold increase of the estimated floc settling velocity highlighting the need of accurate measurements of $d_{p}$ in future works.

Finally, we demonstrated the role of the flocculation in the increase of floc settling velocities. We estimated to one order of magnitude $\left(0.07\right.$ to $\left.0.8 \mathrm{~mm} \mathrm{~s}^{-1}\right)$ the increase of floc settling velocities when floc sizes increased from $<125$ to $>250 \mu \mathrm{m}$ (considering $\alpha / \beta=A R$ and $d_{p}=1 \mu \mathrm{m}$ ). This result emphasized the need to take into account such variability in future model of floc dynamics in ROFI to properly estimate plume sinking rate and SPM dynamics. 


\section{Acknowledgments}

This work was funded by the MATUGLI project under the ANR ASTRID DGA Program and the MISTRALS-MERMEX Program. We thank D. Doxaran (LOV), D. Le Berre and M. Jacquet (IFREMER Brest) for their help. We thank the captain and crews of the $R / V$ Tethys /I for their help during the experiment. This work benefited from helpful comments provided by the editor and anonymous reviewers.

\section{References}

Agrawal, Y.C., Whitmire, A., Mikkelsen, O.A., Pottsmith, H.C., 2008. Light scattering by random shaped particles and consequences on measuring suspended sediments by laser diffraction. J. Geophys. Res. 113 (C4). http://dx.doi.org/10.1029/2007JC004403.

Aminot, A., \& Kérouel, R. 2004. Hydrologie des écosystèmes marins: paramètres et analyses. Editions Quae.

Ayukai, T., Wolanski, E., 1997. Importance of biologically mediated removal of fine sediments from the Fly River plume, Papua New Guinea. Estuar. Coast. Shelf Sci. 44 (5), 629-639. http://dx.doi.org/10.1006/ecss.1996.0172.

Bourrin, F., Durrieu de Madron, X., 2006. Contribution to the study of coastal rivers and associated prodeltas to sediment supply in the Gulf of Lions (NW Mediterranean Sea). Vie et Milieu 56 (4), 307314.

Bourrin, F., Friend, P. L., Amos, C. L., Manca, E., Ulses, C., Palanques, A., Durrieu de MAdron, X., Thompson, C. E. 2008. Sediment dispersal from a typical Mediterranean flood: the Têt River, Gulf of Lions. Continental Shelf Research, 28(15), 1895-1910.

Billiones, R. G., Tackx, M. L., \& Daro, M. H. 1999. The geometric features, shape factors and fractal dimensions of suspended particulate matter in the Scheldt Estuary (Belgium). Estuarine, Coastal and Shelf Science, 48(3), 293-305.

Boss, E., Slade, W., Hill, P., 2009. Effect of particulate aggregation in aquatic environments on the beam attenuation and its utility as a proxy for particulate mass. Opt. Express 17 (11), 9408-9420.

Bushell, G. C., Yan, Y. D., Woodfield, D., Raper, J. U. D. Y., \& Amal, R. O. S. E. 2002. On techniques for the measurement of the mass fractal dimension of aggregates. Advances in Colloid and Interface Science, 95(1), 1-50.

Cauwet, G., Gadel, F., de Souza-Sierra, M.M., Donard, O. and Ewald, M., 1990. Contribution of the Rhone River to organic carbon input to the Northwestern Mediterranean Sea. Cont. Shelf Res. , 10: 1025-1037.

Chakraborti, R.K., Gardner, K.H., Atkinson, J.F., Van Benschoten, J.E., 2003. Changes in fractal dimension during aggregation. Water Research 37, 873e883.

Chakraborti, R. K., Gardner, K. H., Kaur, J., Atkinson, J. F. 2007. In situ analysis of flocs. Journal of Water Supply: Research and Technology-Aqua, 56(1), 1-11. 
Chen, S., Eisma, D., 1995. Fractal geometry of in situ flocs in the estuarine and coastal environments. Neth. J. Sea Res. 32, 173-182.

Clavano, W.R., Boss, E., Karp-Boss, L., 2007. Inherent optical properties of non-spherical marine-like particles-from theory to observation. Oceanogr. Mar. Biol. Annu. Rev. 45, 1-38.

Curran, K.J., Hill, P.S., Milligan, T.G., Mikkelsen, O.A., Law, B.A., Durrieu de Madron, X., Bourrin, F., 2007. Settling velocity, effective density, and mass composition of suspended sediment in a coastal bottom boundary layer, Gulf of Lions, France. Cont. Shelf Res. 27 (10-11), 1408-1421. http://dx.doi.org/10.1016/j.csr.2007.01.014.

Davies, E.J., Nimmo-Smith,W.a.M., Agrawal, Y.C., Souza, A.J., 2011. Scattering signatures of suspended particles: an integrated system for combining digital holography and laser diffraction. Opt. Express 19 (25), 25488-25499.

Davies, E. J., Buscombe, D., Graham, G. W., \& Nimmo-Smith, W. A. M. 2015. Evaluating unsupervised methods to size and classify suspended particles using digital in-line holography. Journal of Atmospheric and Oceanic Technology, 32(6), 1241-1256.

Durrieu de Madron, X., Ferré, B., Le Corre, G., Grenz, C., Conan, P., Pujo-Pay, M., Bodiot, O., Buscail, R. 2005. Trawling-induced resuspension and dispersal of muddy sediments and dissolved elements. Continental Shelf Research, 25 (19-20), 2387-2409.

Durrieu de Madron, X., Ramondenc, S., Berline, L., Houpert, L., Bosse, A., Martini, S., Guidi, L., Conan, P., Curtil, C., Delsaut, N., Kunesch, S., Ghiglione, J.F., Pujo-Pay, M., Séverin, T., Testor, P., Tamburini, C., and the ANTARES collaboration. 2017. Deep sediment resuspension and thick nepheloid layer generation by open-ocean convection. Journal of Geophysical Research - Oceans. doi: 10.1002/2016JC012062

Dyer, K.R., Manning, A.J., 1999. Observation of the size, settling velocity and effective density of flocs, and their fractal dimensions. Journal of Sea Research 41 (1e2), 87-95.

Eisma, D., 1991. Particle size of suspended matter in estuaries. Geo-Mar. Lett. 11 (3-4), 147-153.

Fennessy, M. J., Dyer, K. R., Huntley, D. A. 1994. INSSEV: an instrument to measure the size and settling velocity of flocs in situ. Marine geology, 117(1), 107-117.

Fox, J.M., Hill, P.S., Milligan, T.G., Ogston, A.S., Boldrin, A., 2004. Floc fraction in the waters of the Po River prodelta. Cont. Shelf Res. 24 (15), 1699-1715. http://dx.doi.org/10.1016/j.csr.2004.05.009.

Gangloff, A. 2017. Devenir des apports solides du Rhône dans le Golfe du Lion: étude de la dynamique du panache turbide du Rhône en réponse aux forçages hydrométéorologiques. Thèse de doctorat. IFREMER Brest. 206 p.

Gangloff, A., Verney, R., Doxaran, D., Ody, A., Estournel, C. 2017. Investigating Rhône River plume (Gulf of Lions, France) dynamics using metrics analysis from the MERIS $300 \mathrm{~m}$ Ocean Color archive (2002-2012). Continental Shelf Research, 144, 98-111.

Garnier, J. M., Martin, J. M., Mouchel, J. M., Thomas, A. J. 1991. Surface reactivity of the Rhone suspended matter and relation with trace element sorption. Marine chemistry, 36(1-4), 267-289.

Gohin, F., Stanev, E., 2011. Annual cycles of chlorophyll-a, non-algal suspended particulate matter, and turbidity observed from space and in-situ in coastal waters. Ocean Sci. 7, 705-732. 
Gorsky, G., Ohman, M. D., Picheral, M., Gasparini, S., Stemmann, L., Romagnan, J. B., Cawood, A., Pesant, F., Garcia-Comas, C., Prejger, F. 2010. Digital zooplankton image analysis using the ZooScan integrated system. Journal of plankton research, 32(3), 285-303.

Graham, G.W., Smith, W.a.M., 2010. The application of holography to the analysis of size and settling velocity of suspended cohesive sediments. Limnol. Oceanogr. Methods 8, 1-15.

Graham, G.W., Davies, E.J., Nimmo-Smith, W.a.M., Bowers, D.G., Braithwaite, K.M., 2012. Interpreting LISST-100X measurements of particles with complex shape using digital in-line holography. J. Geophys. Res. 117 (C5), C05034. http://dx.doi.org/10.1029/2011JC007613.

Hill, P. S., Syvitski, J. P., Cowan, E. A., \& Powell, R. D. 1998. In situ observations of floc settling velocities in Glacier Bay, Alaska. Marine Geology, 145(1-2), 85-94.

ISO, I. 2008. 9276-6: 2008 (E), Representation of results of particle size analysis-Part, 6.

Khelifa, A., Hill, P.S., 2006. Models for effective density and settling velocity of flocs. J. Hydraul. Res. 44 (3), 390-401.

Lee, C., \& Kramer, T. A. 2004. Prediction of three-dimensional fractal dimensions using the twodimensional properties of fractal aggregates. Advances in colloid and interface science, 112(1), 49-57.

Maggi, F., Winterwerp, J.C., 2004. Method for computing the threedimensional capacity dimension from two-dimensional projections of fractal aggregates. Physical Review E69, 011405.

Maggi, F., Manning, A. J., Winterwerp, J. C. 2006. Image separation and geometric characterisation of mud flocs. Journal of Hydrology, 326(1), 325-348.

Maillet, G.M., Vella, C., Berné, S., Friend, P.L., Amos, C.L., Fleury, T.J., Normand, A., 2006. Morphological changes and sedimentary processes induced by the December 2003 flood event at the present mouth of the Grand Rhône River (southern France). Mar. Geol. 234 (1-4), 159-177. http://dx.doi.org/10.1016/j.margeo.2006.09.025.

Manning, A. J., Dyer, K. R. 2002. The use of optics for the in situ determination of flocculated mud characteristics. Journal of Optics A: Pure and Applied Optics, 4(4), S71.

Many, G., Bourrin, F., Durrieu de Madron, X., Pairaud, I., Gangloff, A., Doxaran, D., Ody, A., Verney, R., Menniti, C., Le Berre, D., Jacquet, M., 2016. Particle assemblage characterization in the Rhone River ROFI. J. Mar. Syst. 157, 39-51. http://dx.doi.org/10.1016/j.jmarsys.2015.12.010.

Many, G., Bourrin, F., Durrieu de Madron, X., Ody, A., Doxaran, D., Cauchy, P. 2018. Glider and satellite monitoring of the variability of the suspended particle distribution and size in the Rhône ROFI. Progress in Oceanography. 163, 123-135. SI Mermex. http://dx.doi.org/10.1016/j.pocean.2017.05.006.

McCave, I.N., 1975. Vertical flux of particles in the ocean. Deep Sea Res. 22, 491-502.

Mikeš, D., Manning, A. J. 201). Assessment of flocculation kinetics of cohesive sediments from the Seine and Gironde estuaries, France, through laboratory and field studies. Journal of waterway, port, coastal, and ocean engineering, 136(6), 306-318.

Mikkelsen, O. A., Pejrup, M. 2000. In situ particle size spectra and density of particle aggregates in a dredging plume. Marine geology, 170(3), 443-459. 
Mikkelsen, O. A., T. G. Milligan, P. S. Hill, and D. Moffatt. 2004. INSSECT-an instrumented platform for investigating floc properties close to the seabed. Limnol. Oceanogr. Methods. 2: 226-236. doi:10.4319/lom.2004.2.226

Miralles, J., Radakovitch, O., Aloisi, J.C., 2005. 210Pb sedimentation rates from the northwestern Mediterranean margin. Mar. Geol. 216 (3), 155-167. http://dx.doi.org/10.1016/j.margeo.2005.02.020.

Naudin, J.J., Cauwet, G., Chrétiennot-Dinet, M.J., Deniaux, B., Devenon, J.L., Pauc, H., 1997. River discharge andwind influence upon particulate transfer at the land-ocean interaction: case study of the Rhone river plume. Estuar. Coast. Shelf Sci. 45 (3), 303-316. http://dx.doi.org/10.1006/ecss.1996.0190.

Olson, E. 2011. Particle shape factors and their use in image analysis-Part 1: Theory. Journal of GXP Compliance, 15(3), 85.

Owen, R. B., and A. A. Zozulya, 2000: In-line digital holographic sensor for monitoring and characterizing marine particulates. Opt. Eng., 39, 2187-2197, doi:10.1117/1.1305542.

Pont, D., 1996. Evaluation of water fluxes and sediment supply. Oral Communication, MEDDELT, Final Meeting, Venezia, October 2-5.

Sadaoui, M., Ludwig, W., Bourrin, F., Raimbault, P. 2016. Controls, budgets and variability of riverine sediment fluxes to the Gulf of Lions (NW Mediterranean Sea). Journal of Hydrology, 540, 1002-1015.

Simpson, J.H., Sharples, J., 2012. Introduction to the physical and biological oceanography of shelf seas. Cambridge University Press.

Smith, S.J., Friedrichs, C.T., 2011. Size and settling velocities of cohesive flocs and suspended sediment aggregates in a trailing suction hopper dredge plume. Cont. Shelf Res. 31 (10), S50-S63. http://dx.doi.org/10.1016/j.csr.2010.04.002.

Smith, S.J., Friedrichs, C.T. 2015. Image processing methods for in situ estimation of cohesive sediment floc size, settling velocity, and density. Limnology and Oceanography: Methods, 13(5), 250264.

Spicer, P. T., and Pratsinis, S. E. 1996. Shear-induced flocculation: the evolution of floc structure and the shape of the size distribution at steady state. Water Research, 30(5), 1049-1056.

Sternberg, R.W., Berhane, I., Ogston, A.S., 1999. Measurement of size and settling velocity of suspended aggregates on the Northern California continental shelf. Marine Geology 154,43-54.

Tang, S. 1999. Prediction of fractal properties of polystyrene aggregates. Colloids and Surfaces A: Physicochemical and Engineering Aspects, 157(1), 185-192.

Thill, A., Veerapaneni, S., Simon, B., Wiesner, M., Bottero, J. Y., \& Snidaro, D. 1998. Determination of structure of aggregates by confocal scanning laser microscopy. Journal of colloid and interface science, 204(2), 357-362.

Thill, A., Moustier, S., Garnier, J.M., Estournel, C., Naudin, J.J., Bottero, J.Y., 2001. Evolution of particle size and concentration in the Rhône River mixing zone: influence of salt flocculation. Cont. Shelf Res. 21 (18), 2127-2140.

UNESCO, 1983. Algorithms for computation of fundamental properties of seawater.» Technical papers in marine science. 44: 53. 
Vahedi, A., Gorczyca, B., 2011. Application of fractal dimensions to study the structure of flocs formed in lime softening process. Journal of Water Research 45 (2), 545-556.

Van Leussen, W. 1994. Estuarine macroflocs and their role in fine-grained sediment transport. Koninklijke bibliotheek, GIP-Gigevens.

Verney, R., Lafite, R., Brun-Cottan, J. C. 2009. Flocculation potential of estuarine particles: The importance of environmental factors and of the spatial and seasonal variability of suspended particulate matter. Estuaries and coasts, 32(4), 678-693.

Wang, Y. P., Voulgaris, G., Li, Y., Yang, Y., Gao, J., Chen, J., \& Gao, S. 2013. Sediment resuspension, flocculation, and settling in a macrotidal estuary. Journal of Geophysical Research: Oceans, 118(10), 5591-5608.

Winterwerp, J.C., 1998. A simple model for turbulence induced flocculation of cohesive sediment. J. Hydraul. Res. 36 (3), 309-326.

Xia, X. M., Y. Li, H. Yang, C. Y. Wu, T. H. Sing, H. K. Pong. 2004. « Observations on the size and settling velocity distributions of suspended sediment in the Pearl River Estuary, China. "Continental Shelf Research 24 (16): 1809-26. doi:10.1016/j.csr.2004.06.009

Zhou, B., Wang, J., Wang, H. (2017). Three-dimensional sphericity, roundness and fractal dimension of sand particles. Géotechnique, 68(1), 18-30. 